\title{
Efficiency Optimization of a Permanent-Magnet Hybrid Brushless Machine Using DC Field Current Control
}

\author{
Chunhua Liu, K. T. Chau, Wenlong Li, and Chuang Yu \\ Department of Electrical and Electronic Engineering, The University of Hong Kong, Hong Kong, China
}

\begin{abstract}
This paper proposes a new efficiency optimization approach for a new kind of permanent-magnet hybrid brushless (PMHB) machine. The key is to propose the self-searching control (SSC) for the PMHB machine in such a way that the input power at the given load and speed can be progressively minimized by tuning the de field current. A loss analysis of the machine is given to justify the use of dc field current as the control parameter. Detailed experimental results confirm that the proposed approach can effectively accomplish the desired efficiency optimization.
\end{abstract}

Index Terms-Efficiency optimization, field current control, permanent-magnet (PM) machine, self-searching control (SSC).

\section{INTRODUCTION}

W ITH ever-increasing concern on energy efficiency, various efficiency optimization approaches have been developed for electric machines, including the permanent-magnet (PM) brushless machines [1] which inherently have relatively high efficiency [2]. Basically, such approaches are loss-model referencing, model-free self-searching, or even both of them [3]. Although self-searching control (SSC) takes advantage of model-free self-searching, which is insensitive to parameter variations and is easy-to-implement, it still relies on using the $d-q$ coordinate transformation to perform flux control. Recently, a new class of PM hybrid brushless (PMHB) machines [4]-[6] has been developed which offers the distinct feature of simple flux control.

The purpose of this paper is to propose the SSC for efficiency optimization of the PMHB machine. The key is to use the dc field windings of the PMHB machine to online tune the air-gap flux, and consequently adjust the input power under the given load and speed. Hence, the advantages of SSC can be retained while there is no need to use the complicated $d-q$ coordinate transformation.

\section{PRINCIPLE OF EFFICIENCY OPTIMIZATION}

Fig. 1 shows the newly developed PMHB machine. It is composed of a solid-iron outer rotor with 24 salient poles, and a double-layered stator in which the outer stator has 36 salient poles wound with armature windings, while the inner stator has installed both PMs and dc field windings for hybrid-field excitation. The air bridge, which is in shunt with each PM, functions to amplify the effect of flux control. Through proper control of the bidirectional dc field current, this machine can realize flexible flux control up to a range of nine times.

The proposed control system for efficiency optimization is depicted in Fig. 2. It can be seen that the dc field current control essentially decouples with the machine operation control, which

Manuscript received March 02, 2009. Current version published September 18, 2009. Corresponding author: C. Liu (e-mail: chualiu@eee.hku.hk).

Digital Object Identifier 10.1109/TMAG.2009.2021402

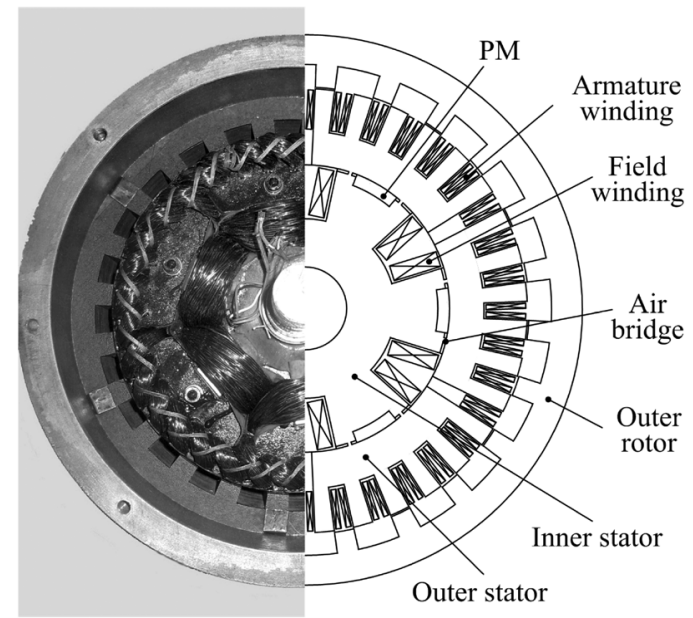

Fig. 1. PMHB machine configuration.

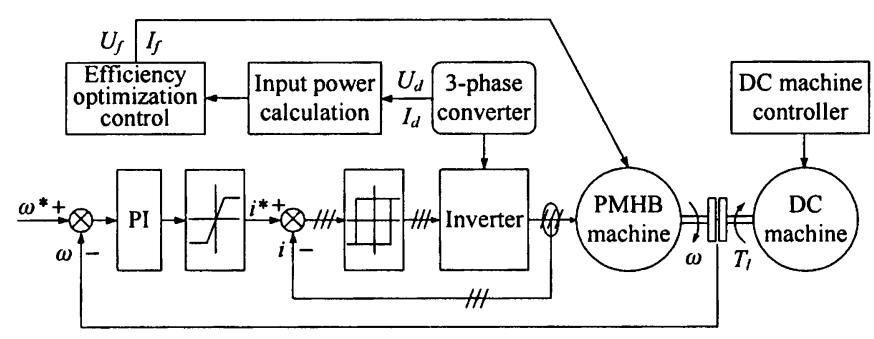

Fig. 2. Proposed control system for efficiency optimization.

makes the efficiency optimization simple and reliable. The key of this efficiency-optimizing control is as follows: when the algorithm starts, it will check the optimal operation record to see whether it has stored the corresponding load torque and speed. If yes, it will retrieve the optimal parameters; if not, it will perform the SSC, namely to online tune the dc field current in such a way that the input power of the whole system can be progressively minimized under the given load and speed. After completing the SSC, the data will be used to update the optimal operation record. Fig. 3 shows the power circuit for dc field current control, which is actually a typical H-bridge converter. Hence, the magnitude of the dc field current can be easily regulated by adjusting the duty cycle of the conductive switches. Also, the direction of the dc field current can be simply controlled 


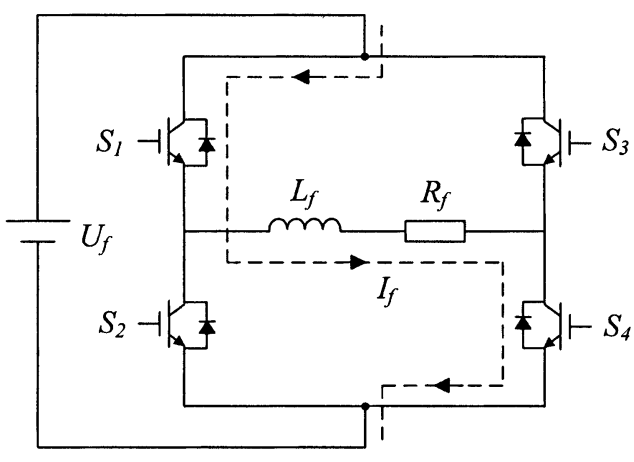

Fig. 3. Power circuit for dc field current control.

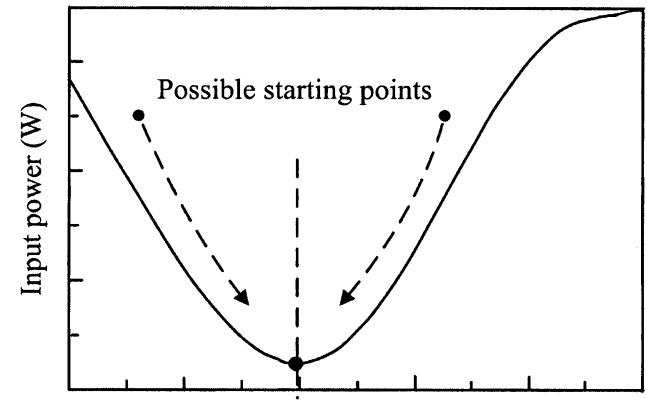

Field current (A)

Fig. 4. SSC process for efficiency optimization.

TABLE I

SSC PERTURBATION RULE FOR EFFICIENCY OPTIMIZATION

\begin{tabular}{|c|c|c|c|}
\hline $\begin{array}{c}\text { Current } \\
\text { perturbation }\end{array}$ & $\begin{array}{c}\text { Change in } \\
\text { field current }\end{array}$ & $\begin{array}{c}\text { Change in } \\
\text { input power }\end{array}$ & $\begin{array}{c}\text { Next } \\
\text { perturbation }\end{array}$ \\
\hline Positive & Positive & Negative & Positive \\
\hline Negative & Negative & Positive & Positive \\
\hline Positive & Positive & Positive & Negative \\
\hline Negative & Negative & Negative & Negative \\
\hline
\end{tabular}

by selecting contrary switches. As compared with other efficiency optimization approaches, the proposed method has the merits of simpler control, easier implementation, and is more cost-effective.

Fig. 4 shows the SSC process for efficiency optimization of the PMHB machine under the given load and speed. If the starting point is from the left-hand side of the minimum input power point, the increment of the dc field current will reduce the input power. In contrast, if the starting point goes from the right-hand side of the minimum input power point, the decrement of the dc field current will reduce the input power. Therefore, if there is a decrease in input power, the subsequent perturbation will be kept unchanged until reaching the minimum input power point; otherwise, the perturbation will be reversed. This perturbation rule is summarized in Table I. Additionally, once the optimal point of a specific condition is obtained, this operation point is memorized and will be used as the initial point for next search or be directly used as the optimal operation point if encountering this condition again. This arrangement can greatly enhance the speed of searching. It should be noted that since the input power is measured on the dc link, the efficiency optimization is for the entire drive system, including the PMHB machine and power inverter.

\section{LOSS ANALYSIS}

The major losses of the PMHB machine include the copper losses, iron losses, stray losses, and mechanical losses. The iron losses are composed of the magnetic hysteresis loss and eddycurrent loss [7], [8].

The copper losses are due to the stator windings and dc field windings, which can be written by

$$
\begin{aligned}
P_{\mathrm{Cu}} & =m R_{a} i_{a}^{2}+R_{f} I_{f}^{2} \\
u_{a} & =R_{a} i_{a}+L_{a} \frac{d i_{a}}{d t}+e_{a} \\
e_{a} & =C_{e} \Phi_{\delta} n \\
\Phi_{\delta} & =k_{1} \tau l_{a} B_{\delta}
\end{aligned}
$$

where $m$ is the number of phases, $R_{a}$ the resistance of the phase winding, $i_{a}$ the current, $R_{f}$ the resistance of the dc field winding, $I_{f}$ the field current, $u_{a}$ the terminal phase voltage, $L_{a}$ the inductance of the phase end winding, $e_{a}$ the generated phase electromagnetic field, $C_{e}$ the coefficient of the phase electromagnetic field, $\Phi_{\delta}$ the phase flux linkage, $n$ the machine speed, $k_{1}$ the coefficient of the pole arc, $\tau$ the pole pitch, $l_{a}$ the axial length, and $B_{\delta}$ the air-gap flux density. Substituting (3) and (4) in (2), it yields

$$
u_{a}=R_{a} i_{a}+L_{a} \frac{d i_{a}}{d t}+k_{1} \tau l_{a} C_{e} n B_{\delta} .
$$

From (1) and (5), it can be deduced that the copper losses are mainly governed by the stator current and the field current, while the stator current can be adjusted by changing $B_{\delta}$ which can also be regulated by tuning the field current.

Classically, the iron losses of the teeth and yokes can be expressed as

$$
P_{\mathrm{Fe}}=k_{2} k_{3} G_{t}\left(\frac{f}{50}\right)^{1.3} B_{t}^{2}+k_{2} k_{3} G_{y}\left(\frac{f}{50}\right)^{1.3} B_{y}^{2}
$$

where $k_{2}$ and $k_{3}$ are the coefficients of iron losses, $G_{t}$ and $G_{y}$ the weights of teeth and yokes, $f$ the supply frequency, and $B_{t}$ and $B_{y}$ the flux densities of teeth and yokes. Thus, under the given speed, the iron losses can be adjusted by regulating $B_{t}$ and $B_{y}$, which can also be controlled by tuning the field current.

For higher accuracy, the iron losses can be expressed in terms of the magnetic hysteresis loss and the eddy-current loss. The magnetic hysteresis loss is caused by varying magnetization of ferromagnetic materials, which can be written by

$$
P_{\mathrm{Hy}}=k_{4} G_{\mathrm{Fm}} f B_{\sigma}+k_{5} G_{\mathrm{Fm}} f B_{\sigma}^{2}
$$

where $k_{4}$ and $k_{5}$ are the coefficients of the materials, $G_{\mathrm{Fm}}$ the weight of the ferromagnetic material, and $B_{\sigma}$ the flux density of the iron. Hence, under the given speed, the magnetic hysteresis loss varies with $B_{\sigma}$, which can also be adjusted by the field current. On the other hand, the eddy-current loss exists in the iron, which can be described by

$$
P_{\mathrm{Ed}}=\frac{\pi^{2} b^{2}}{6 \rho_{1} \rho_{2}} G_{\mathrm{Fe}} f^{2} B_{\sigma}^{2}
$$




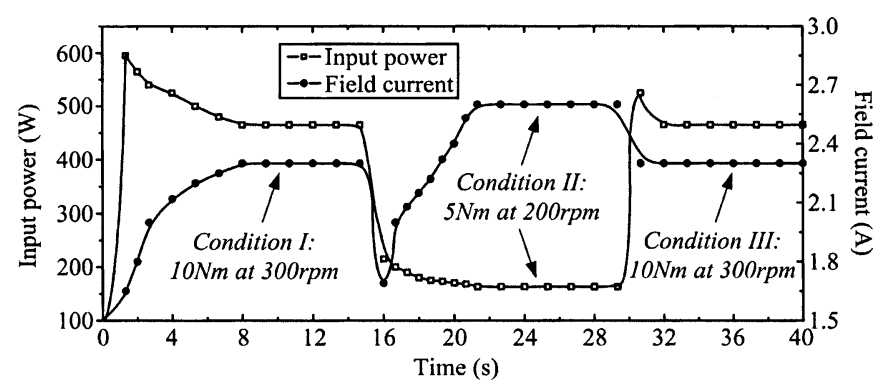

Fig. 5. Measured input power and field current responses with efficiency optimization during flux strengthening.

where $b$ is the thickness of the iron, $\rho_{1}$ the resistivity of the iron, $\rho_{2}$ the density of the iron, and $G_{\mathrm{Fe}}$ the weight of the iron. Thus, under the given speed, the eddy-current loss is related with $B_{\sigma}$, which can also be regulated by the field current.

The stray losses are additional losses caused by the load current due to changes in metallic materials. Such losses are usually quite small and can be expressed as

$$
P_{\mathrm{St}}=k_{6} f^{2} i_{a}^{2}
$$

where $k_{6}$ is the coefficient of stray losses. According to (5), it can be seen that the stray losses can be altered by adjusting $B_{\delta}$, which can also be changed by tuning the field current.

The mechanical losses are due to friction and windage, which are independent from those electrical variables. In general, they can be written by

$$
P_{\mathrm{Me}}=k_{7} n^{2}
$$

where $k_{7}$ is the coefficient of mechanical losses.

Therefore, except the mechanical losses, all the other losses can be regulated by tuning the field current under the given load and speed. Hence, the optimal efficiency of the PMHB machine can be expressed as

$$
\eta_{\text {opt }}=\left(1-\frac{P_{\text {loss_opt }}}{P_{\text {out }}+P_{\text {loss_opt }}}\right) \times 100 \%
$$

where $P_{\text {loss }}=\sum\left(P_{\mathrm{Cu}}+P_{\mathrm{Fe}}+P_{\mathrm{St}}+P_{\mathrm{Me}}\right)$ is the total losses, and $\eta_{\text {opt }}$ is the optimal efficiency.

\section{RESULTS}

The proposed efficiency optimization of the PMHB machine has been prototyped for experimentation. This PMHB machine is mechanically coupled with a dc machine. By connecting with a four-quadrant programmable power supply, this dc machine operates as a dynamometer which can real-time control the rotor speed and load torque.

First, the proposed efficiency optimization of the PMHB machine is assessed during flux strengthening. Fig. 5 shows the measured input power and field current responses under different loads and speeds. It can be seen that in Condition I $(10 \mathrm{Nm}$ at $300 \mathrm{rpm}$ ), the field current gradually increases until the input power progressively reaches the minimum of $465 \mathrm{~W}$. When the operation is suddenly changed to Condition II ( $5 \mathrm{Nm}$ at $200 \mathrm{rpm}$ ), a new search is activated. Consequently, the input

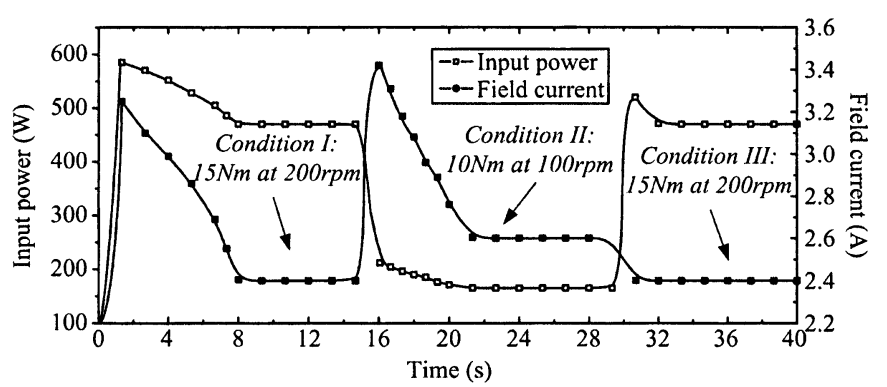

Fig. 6. Measured input power and field current responses with efficiency optimization during flux weakening.

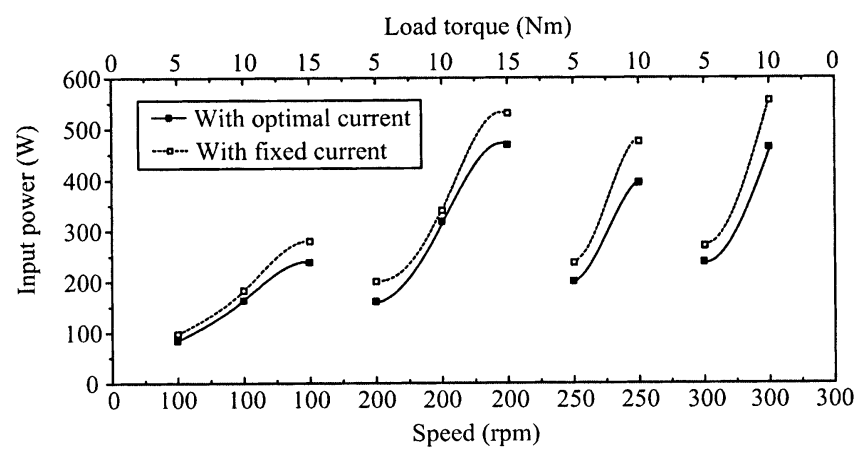

Fig. 7. Measured input power characteristics with and without efficiency optimization.

power is minimized to $163 \mathrm{~W}$ with the optimal field current of $2.6 \mathrm{~A}$. When the operation is suddenly switched to Condition III which is actually the same as Condition I, the initial operation point is directly retrieved from the memory. So, it virtually takes no time to achieve the minimum input power of $465 \mathrm{~W}$. Hence, it verifies that the proposed SSC method can effectively find the optimal operation point during flux strengthening for the PMHB machine under different loads and speeds.

Second, the proposed efficiency optimization is evaluated during flux weakening. Fig. 6 shows the measured input power and field current responses under different loads and speeds. It can be found that in Condition I (15 Nm at $200 \mathrm{rpm})$, the field current decreases until the input power gradually arrives at the minimum of $470 \mathrm{~W}$ with the optimal current of $2.4 \mathrm{~A}$. While the operation is suddenly changed to Condition II $(10 \mathrm{Nm}$ at $100 \mathrm{rpm}$ ), another new search is triggered. Then, the input power is minimized to $165 \mathrm{~W}$. When the operation suddenly returns to the same case as Condition I, the initial operation point is directly retrieved from the memory. Thus, it quickly settles at the minimum input power of $470 \mathrm{~W}$. Hence, it further verifies the effectiveness of the proposed SSC.

Third, in order to evaluate the validity of the proposed efficiency optimization, the input power characteristics of the PMHB machine with the use of optimal field current and a fixed field current of $2 \mathrm{~A}$ are compared as shown in Fig. 7. It can be seen that under any sets of rotor speed and load torque, the input power with the optimal field current is always less than that with the fixed field current. The corresponding percentage reduction in input power is also plotted in Fig. 8. It can be seen that the input power reduction spans from $5.9 \%$ to $18.5 \%$, and 


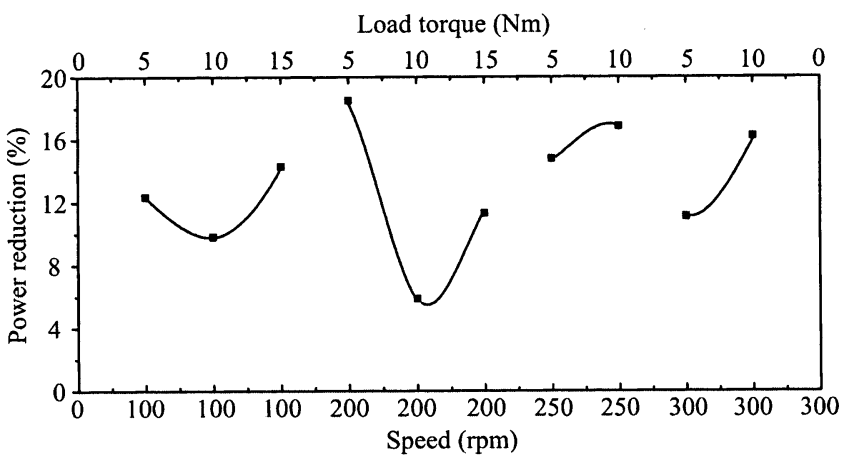

Fig. 8. Measured power reduction characteristics with efficiency optimization.

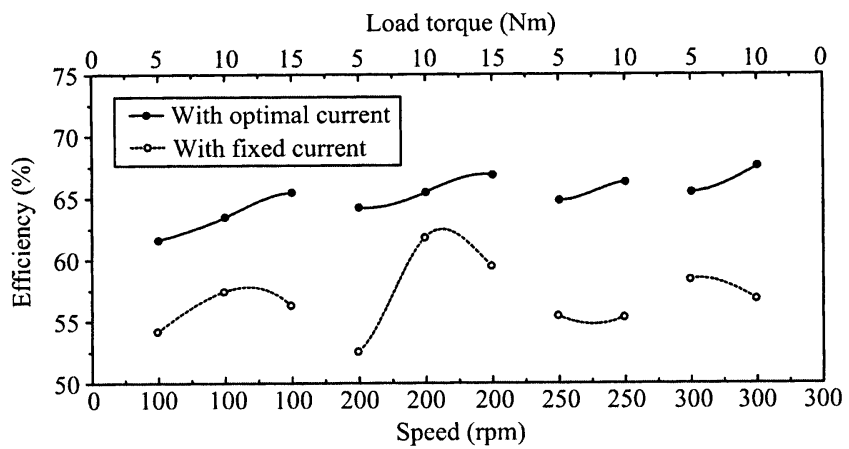

Fig. 9. Measured efficiency characteristics with and without efficiency optimization.

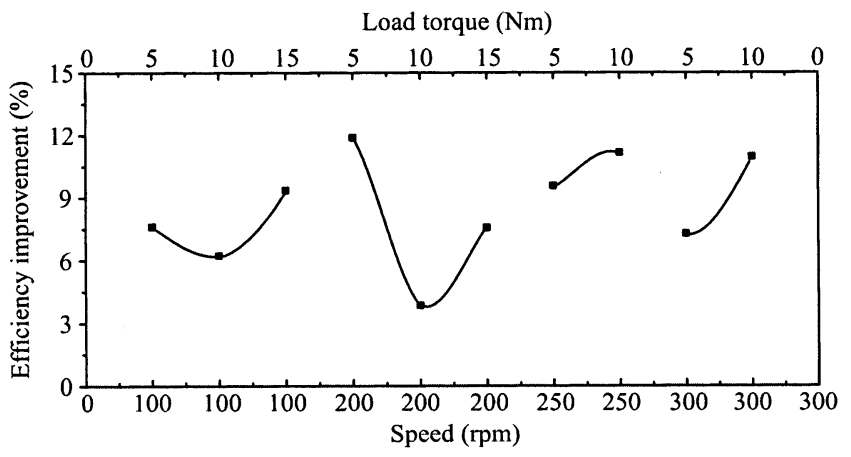

Fig. 10. Measured efficiency improvement characteristics with efficiency optimization.

mostly over $10 \%$. Such reduction is very significant when the power level is elevated to the order of kilowatts.

Fourth, to further assess the efficiency improvement, the measured efficiency characteristics with the optimal field current and a fixed field current of $2 \mathrm{~A}$ are also compared as depicted in Fig. 9. It can be found that the efficiency with the optimal current spans from $61.6 \%$ to $67.6 \%$, which is much higher than the range of $52.3 \%-61.5 \%$ with the fixed field current. The corresponding efficiency improvement is also shown in Fig. 10.
It can be seen that the efficiency improvement is significant, from $3.9 \%$ to $11.9 \%$, and mostly over $7 \%$. Therefore, with the proposed efficiency optimization, the PMHB machine can significantly improve its efficiency, and consequently increase its cost-effectiveness.

Furthermore, it is worthy to note that since the input power is measured at the dc link, the measured efficiency is actually a combined efficiency of the whole system, including the PMHB machine and power inverter. So, the optimal efficiency of over $61.6 \%$ under all speeds and loads is attractive for most industrial applications.

\section{CONCLUSION}

A new efficiency-optimizing approach for the PMHB machine has been proposed and implemented. The loss analysis indicates that various loss components of the machine can be altered by changing the dc field current. So, by simply tuning the dc field current, this machine can online achieve the minimum input power under any given loads and speeds. Detailed experimental results have been given to verify that the proposed approach is effective to achieve the desired optimal efficiency.

\section{ACKNOWLEDGMENT}

This work was supported and funded by a grant (Project No. HKU7105/07E) from the Research Grants Council, Hong Kong Special Administrative Region, China.

\section{REFERENCES}

[1] K. T. Chau, C. C. Chan, and C. Liu, "Overview of permanent-magnet brushless drives for electric and hybrid electric vehicles," IEEE Trans. Indus. Electron., vol. 55, no. 6, pp. 2246-2257, Jun. 2008.

[2] D.-J. Sim, D.-H. Cho, J.-S. Chun, H.-K. Jung, and T.-K. Chung, "Efficiency optimization of interior permanent magnet synchronous motor using genetic algorithms," IEEE Trans. Magn., vol. 33, no. 2, pp. 1880-1883, Mar. 1997.

[3] D. de Almeida Souza, W. C. P. de Aragão Filho, and G. C. D. Sousa, "Adaptive fuzzy controller for efficiency optimization of induction motors," IEEE Trans. Indus. Electron., vol. 54, no. 4, pp. 2157-2164, Aug. 2007.

[4] K. T. Chau, Y. B. Li, J. Z. Jiang, and C. Liu, "Design and analysis of a stator-doubly-fed doubly-salient permanent-magnet machine for automotive engines," IEEE Trans. Magn., vol. 42, no. 10, pp. 3470-3472, Oct. 2006.

[5] K. T. Chau, Y. B. Li, J. Z. Jiang, and S. Niu, "Design and control of a PM brushless hybrid generator for wind power application," IEEE Trans. Magn., vol. 42, no. 10, pp. 3497-3499, Oct. 2006.

[6] C. Liu, K. T. Chau, J. Z. Jiang, and L. Jian, "Design of a new outer-rotor permanent magnet hybrid machine for wind power generation," IEEE Trans. Magn., vol. 44, no. 6, pp. 1494-1497, Jun. 2008.

[7] O. Bottauscio, A. Canova, M. Chiampi, and M. Repetto, "Iron losses in electrical machines: Influence of different material models," IEEE Trans. Magn., vol. 38, no. 2, pp. 805-808, Mar. 2002.

[8] S. Niu, K. T. Chau, and J. Z. Jiang, "Eddy-current loss in a double-stator PM machine," IEEE Trans. Magn., vol. 44, no. 11, pp. 4401-4404, Nov. 2008. 